\title{
8
}
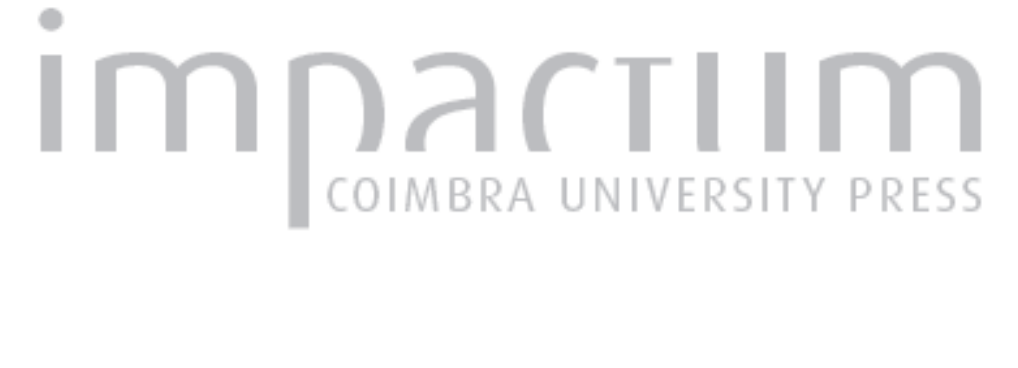

Desafios da Política Externa Europeia no Cáucaso do Sul: os Limites da Geopolítica de Base Normativa
Autor(es):
Simão, Licínia

Publicado por: Imprensa da Universidade de Coimbra

URL persistente:

URl:http://hdl.handle.net/10316.2/43548

DOI:

DOI:https://doi.org/10.14195/1647-6336_18_6

Accessed : $\quad$ 26-Apr-2023 16:31:31

A navegação consulta e descarregamento dos títulos inseridos nas Bibliotecas Digitais UC Digitalis, UC Pombalina e UC Impactum, pressupõem a aceitação plena e sem reservas dos Termos e Condições de Uso destas Bibliotecas Digitais, disponíveis em https://digitalis.uc.pt/pt-pt/termos.

Conforme exposto nos referidos Termos e Condições de Uso, o descarregamento de títulos de acesso restrito requer uma licença válida de autorização devendo o utilizador aceder ao(s) documento(s) a partir de um endereço de IP da instituição detentora da supramencionada licença.

Ao utilizador é apenas permitido o descarregamento para uso pessoal, pelo que o emprego do(s) título(s) descarregado(s) para outro fim, designadamente comercial, carece de autorização do respetivo autor ou editor da obra.

Na medida em que todas as obras da UC Digitalis se encontram protegidas pelo Código do Direito de Autor e Direitos Conexos e demais legislação aplicável, toda a cópia, parcial ou total, deste documento, nos casos em que é legalmente admitida, deverá conter ou fazer-se acompanhar por este aviso.

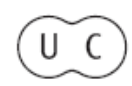




\section{DEBATER \\ A EUROPA}

jan-jun 2018

RELACCÕES EXTERNAS DA

UNIÃO EUROPEIA A LESTE

EXTERNAL RELATIONS OF THE

EUROPEAN UNION TOWARDS THE EAST 


\section{Desafios da Política Externa Europeia no Cáucaso do Sul: Os Limites da Geopolítica de Base Normativa European Foreign Policy Challenges in the South Caucasus: The Limits of a Normative-Based Geopolitics}

Licínia Simão

Faculdade de Economia e Centro de Estudos Sociais, Universidade de Coimbra lsimao@fe.uc.pt

\section{Resumo:}

Este artigo analisa as relações da União Europeia (UE) com os países do Cáucaso do Sul, Arménia, Azerbaijão e Geórgia, no âmbito da Política Europeia de Vizinhança (PEV). A análise centra-se na interação entre a exportação dos modelos de governação e normas europeias e as ambições geopolíticas e de segurança da União. $\mathrm{O}$ argumento central defende que a ação securitária da UE, nomeadamente na transformação positiva dos conflitos armados da região, tem sido limitada pela abordagem despolitizada que a PEV promove e que beneficiaria de uma abordagem onde a dimensão política do modelo de estabilização regional da UE fosse assumida.

Palavras chave: União Europeia, Cáucaso do Sul, Política Europeia de Vizinhança, governação, geopolítica

\section{Abstract:}

This article analyses EU relations with the South Caucasus countries, Armenia, Azerbaijan and Georgia, within the European Neighbourhood Policy (ENP). The analysis centers on the interaction between the export of governance models and European norms and the security and geopolitical ambitions of the Union. The central argument states that the security action of the EU, namely in the positive transformation of the armed conflicts in the region, has been limited by a depoliticized approach that the ENP promotes and that would benefit from an approach where the political dimension of the regional stabilization model of the EU would be acknowledged. 
Keywords: European Union, South Caucasus, European Neighbourhood Policy, governance, geopolitics

\section{Introdução}

As relações da União Europeia (UE) com os países do Cáucaso do Sul, Arménia, Azerbaijão e Geórgia iniciaram-se logo na década de 1990, com as declarações formais de independência que anunciavam o colapso da União Soviética. ${ }^{1}$ Nesta fase inicial, que se estende até ao final da década, a política externa das Comunidades Europeias para a região refletiu simultaneamente as suas limitações políticas e institucionais e alguma divisão de trabalho com a Federação Russa na gestão da instabilidade no espaço pan-Europeu. Assim, até à inclusão destes três países na Política Europeia de Vizinhança (PEV), em 2004, as relações da UE com a região limitaram-se à ação humanitária e reabilitação, nomeadamente nas zonas envolventes aos conflitos na Abecásia, Ossétia do Sul e Nagorno-Karabakh, ao apoio indireto à mediação promovida pela Organização das Nações Unidas (ONU) e pela Organização para a Segurança e Cooperação na Europa (OSCE)², bem como à celebração de acordos bilaterais, os Acordos de Parceria e Cooperação, que definiriam a base do relacionamento futuro.

No final da década de 1990, a situação securitária na região do Cáucaso deteriorou-se significativamente, fruto da segunda guerra da Chechénia, na Federação Russa, e da forte instabilidade dos regimes da região, afetando o seu desenvolvimento político, económico e social. Gradualmente, alguns Estados membros da UE, assim como o Parlamento Europeu, iniciaram um conjunto de reflexões internas sobre a necessidade de desenvolver um pacto de estabilidade para o Cáucaso do Sul. Este interesse europeu reflete também a crescente importância estratégica que os países da região ganharam com o desenvolvimento dos primeiros projetos que ligavam as reservas energéticas do Cáspio aos mercados europeus, sem transitar por território russo. O futuro alargamento da UE a leste, previsto para 2004, exigia também algum envolvimento com a região e a sua estabilização.

Contudo, e apesar deste interesse estratégico, no lançamento da PEV em 2003, os países do Cáucaso do Sul não foram incluídos, "devido à sua localização geográfica" (Comissão Europeia, 2003: 4). Esta explicação formal algo simplista torna opacas as razões pelas quais a região foi considerada como não-elegível para a PEV, em 2003. Estas incluem as complexas relações securitárias da região e o entendimento, em vários Estados membros, de que o Cáucaso do Sul era parte de uma área de interesses privilegiados da Rússia (Popescu, 2011). Até à Revolução das Rosas na Geórgia em 2003, não existiam incentivos

1 Para uma introdução à região do Cáucaso do Sul ver de Waal (2010).

2 Para uma análise bem informada sobre os conflitos armados do Cáucaso do Sul ver de Waal (2003), Lynch (2004), Cornell (2000) e Welt (2004). 
claros para a inclusão da região na $\mathrm{PEV}$, já que esta iniciativa se centrava na promoção de padrões de governação democrática e de modernização económica. A partir de 2003, a perspetiva de estabilização da Geórgia permitia agora abrir corredores de escoamento da produção energética do Cáspio para mercados europeus, suscitando interesse renovado dos Estados da UE e das suas instituições.

A mudança de regime na Geórgia, iniciada em novembro de 2003 e confirmada com a eleição de Mikheil Saakashvili como Presidente do país em janeiro de 2004, instigou a UE a envolver-se de forma mais visível. Num primeiro momento, destacou o Alto Representante para a Política Europeia de Segurança Comum (PESC), Javier Solana, para Tbilisi para mediar a crise política (Solana, 2004) e posteriormente autorizou uma missão da Política Europeia de Segurança e Defesa (PESD) de Estado de Direito, a EUJUST THEMIS, para apoiar o governo georgiano na reforma do seu sistema judiciário (Conselho da UE, 2004a; Helly, 2006). A UE disponibilizou também fundos de emergência através do Instrumento para a Estabilidade, que visavam atenuar as consequências imediatas da crise política. A um nível mais estrutural, articularam-se argumentos no Conselho sobre a importância de apoiar a democratização da região do Cáucaso do Sul através da sua inclusão na PEV (Lynch, 2006). Numa fase inicial, a UE privilegiou uma abordagem regional, ilustrada pela nomeação de um Representante Especial da UE (REUE) para o Cáucaso do Sul, em julho de 2003, cujo mandato foi renovado e reforçado nos meses e anos seguintes (Conselho da UE, 2003a, 2003b, 2004b, 2005). A Comissão Europeia, encarregue de gerir a PEV, e alguns Estados membros passaram a ver a Geórgia como um líder regional na sua relação com Bruxelas, esperando-se que pudesse atuar como um incentivo nas relações da UE com a Arménia e o Azerbaijão (Simão, 2013). Para além disso, a abordagem regional da UE justificava-se também pela perceção de que o Cáucaso constitui um complexo regional de segurança (Coppieters, 1996; Simão e Freire, 2008), requerendo uma ação concertada no que toca à transformação dos conflitos regionais - uma área onde o maior envolvimento da UE poderia ter efeitos positivos.

Assim, no Documento Estratégico da PEV de 2004, a Comissão Europeia recomendava a inclusão dos países do Cáucaso do Sul nesta política e iniciou negociações bilaterais com vista à definição de uma abordagem diferenciada às necessidades de cada um destes Estados (Comissão Europeia, 2004: 10). O Parlamento Europeu promoveu ativamente um envolvimento da UE à escala regional, recomendando que a União prestasse mais atenção aos conflitos (Parlamento Europeu, 2006; 2010). Efetivamente, apesar da relutância da UE em se envolver de forma mais direta nos processos de mediação e de manutenção da paz em vigor, a verdade é que a ajuda humanitária e de reabilitação da UE lhe tinham garantido, já em 2001, um lugar de observadora na Comissão de Controlo Partilhado para a Ossétia do $\mathrm{Sul}^{3}$ (Popescu, 2011; Simão, 2014). Um relatório do International Crisis Group

3 Este é o formato oficial de mediação do conflito da Ossétia do Sul. Foi estabelecido em 1992, após a assinatura do acordo de cessar-fogo, e junta o Governo da Geórgia, a Federação Russa, as autoridades 
de 2006 sublinhava o potencial de resolução de conflitos dos diferentes instrumentos e políticas da PEV (ICG, 2006), incluindo as sinergias positivas que poderiam resultar da articulação dos objetivos da PEV com o trabalho do REUE. Depois da guerra de 2008 na Geórgia, a Presidência francesa da UE liderou o processo negocial que conduziu à assinatura de um cessar-fogo entre a Geórgia e a Federação Russa e, perante o veto russo relativo à renovação do mandato da Missão de Observação das Nações Unidas na Geórgia (UNOMIG), o Conselho autorizou de forma célere a formação de uma missão de observação para a Geórgia, a EU Monitoring Mission (EUMM). Para além disso, o REUE passou a ter um papel central nas Negociações Internacionais de Genebra. ${ }^{4}$ Com estes passos, podemos dizer que Bruxelas assumiu assim um papel mais prominente nas dinâmicas de resolução de conflitos na Geórgia (Whitman e Wolff, 2010).

Desde o estabelecimento da PEV em 2003, a UE tem sido incapaz de desenvolver uma parceria sólida com a Federação Russa. Moscovo recusou participar na PEV e, em vez disso, procurou instituir uma parceria estratégica com a UE, com base na negociação de quatro espaços comuns (Federação Russa e União Europeia, 2003). Contudo, esta iniciativa tem vindo a esvaziar-se à medida que a UE aprofunda as suas relações com os países da ex-União Soviética, onde a Rússia considera ter interesses privilegiados. Assim, após a revolução Laranja na Ucrânia em 2004, as relações de Moscovo com Bruxelas e com várias capitais europeias tornaram-se ainda mais tensas, impossibilitando quaisquer avanços significativos no âmbito do terceiro espaço comum, de Cooperação no campo da Segurança Externa, nomeadamente no que toca aos conflitos regionais (Samokhvalov, 2007). Para além disso, a abertura do oleoduto Bacu-Tbilisi-Ceyhan (BTC) e do gasoduto Bacu-Tbilisi-Erzurum (BTE), fornecendo petróleo e gás natural, respetivamente, aos mercados europeus sem passar por território russo, contribuiu ainda mais para a acumulação de frustrações e tensões nas relações da UE com Moscovo (Starr e Cornell, 2005).

É neste contexto que as relações da UE com a Arménia, o Azerbaijão e a Geórgia têm evoluído ao longo da última década. Na secção seguinte olhamos para os acordos políticos que foram celebrados, começando com a negociação dos Planos de Ação (PA) da PEV e os Acordos de Associação (AA), assim como as iniciativas regionais, para entender a natureza das relações entre estes Estados e Bruxelas. O artigo olha depois para as relações na área económica e para as negociações em torno da liberalização de vistos, como dois aspetos centrais na forma como a UE é percecionada pelos seus vizinhos, nas dinâmicas dos conflitos e na exportação de influência da UE para a vizinhança partilhada com a Rússia. Ao longo da análise, o artigo procura entender de que forma a PEV tem

não-reconhecidas da Ossétia do Sul e representantes da Ossétia do Norte. Em 2008, o Governo da Geórgia abandonou formalmente este formato negocial, por considerá-lo ultrapassado e desajustado.

4 Este formato negocial é presidido pela OSCE, a UE e a ONU. Participam nas discussões o Governo da Geórgia, da Ossétia do Sul e da Abecásia, bem como a Rússia e os Estados Unidos. 
dado resposta às ambições geopolíticas da UE e tem permitido à União ser coerente com o seu discurso normativo.

\section{Definição da Base Legal e Política das Relações UE-Cáucaso do Sul}

As relações da UE com a Arménia, Azerbaijão e Geórgia têm como base legal os Acordos bilaterais de Parceria e Cooperação (APC), negociados e assinados na década de 1990. Os APC, negociados entre a UE e todos os países da ex-União Soviética, são acordos amplos, centrados na promoção de reformas democráticas e da economia de mercado, bem como no desenvolvimento de cooperação multissetorial. No âmbito da PEV, em 2003, foram negociados Planos de Ação bilaterais, definindo passos concretos que permitissem aos vizinhos da UE aproximar-se do quadro legislativo, normativo e político da UE. Contudo, estes documentos não constituem uma nova base legal para a relação, já que os APC se mantêm vigentes, e por isso o futuro estatuto destes Estados face à União manteve-se muito ambíguo. Na medida em que a inclusão na PEV criou expetativas nos países do Cáucaso do Sul face a uma possível adesão à UE, este processo manteve-se aberto, indefinido e claramente baseado numa base política e legal que não reflete os novos contextos locais, regionais e internacionais, em mudança acelerada.

No que toca à resolução de conflitos, os APC são extremamente vagos (Conselho da UE e Comissão Europeia, 1999a; 1999b; 1999c). Os Planos de Ação da PEV foram apenas ligeiramente mais ambiciosos neste aspeto, normalmente referindo a conflitualidade como um obstáculo à cooperação económica regional, incluindo em matérias energéticas e de transportes. Na ausência de um acordo político forte e vinculativo com a UE, a condicionalidade ligada ao progresso nos processos de paz foi extremamente fraca (Sasse, 2008). Na revisão da PEV de 2015, a UE defende que quer a União, quer os seus vizinhos devem estar comprometidos na promoção da cooperação no setor da segurança, com potenciais impactos nas dinâmicas dos conflitos regionais (Comissão Europeia e Alta Representante da União Europeia para os Negócios Estrangeiros e a Política de Segurança, 2015b: 4).

Os Planos de Ação são, portanto, ferramentas políticas fracas que lidam com as dinâmicas dos conflitos apenas na medida em que os Governos da Arménia, do Azerbaijão e da Geórgia o consideraram urgente e necessário. Para o Governo da Geórgia, a partir da Revolução das Rosas, o envolvimento da UE nos conflitos da Abecásia e da Ossétia do Sul passou a ser visto como um passo fundamental para reequilibrar os formatos negociais existentes, que Tbilisi entendia serem injustos e desfavoráveis. Para o Presidente Saakashvili, da Geórgia, a internacionalização dos conflitos e o apoio da UE à integridade territorial da Geórgia foram objetivos centrais dos seus mandatos (IIFFMCG, 2009). Assim, o Plano de Ação UE-Geórgia inclui a prioridade número seis como sendo a "Promoção da resolução pacífica dos conflitos internos" (Comissão Europeia, 2006c). 
No caso da Arménia e do Azerbaijão, uma prioridade sobre "resolução pacífica do conflito de Nagorno-Karabakh" também foi incluída, sendo que no Plano de Ação da Arménia é a prioridade número sete e para o Azerbaijão é a prioridade número um (Comissão Europeia, 2006a; 2006b). Se no caso da Geórgia a UE se comprometeu com uma série de passos importantes com potencial impacto nas dinâmicas dos conflitos, incluindo um aumento da assistência económica à Geórgia e diálogo político com a Federação Russa e outros atores relevantes; no caso do conflito de Nagorno-Karabakh, os esforços da UE visaram apoiar o trabalho do REUE e do Grupo de Minsk da OSCE. ${ }^{5}$

De uma forma geral, o contributo da UE para a resolução de conflitos através dos Planos de Ação da PEV tem sido bastante limitado (Helly, 2007; Sasse, 2009). Na realidade, ao aprofundar as suas relações com a Geórgia, a UE ficou refém das posições de Tbilisi no que toca aos conflitos, nomeadamente ao reconhecer a integridade territorial da Geórgia, e foi incapaz de ser um mediador neutro entre o Governo georgiano e as autoridades na Abecásia e na Ossétia do Sul (Coppieters, 2007), ou entre a Geórgia e a Federação Russa. No caso de Nagorno-Karabakh, nenhum REUE conseguiu visitar a região devido à pressão exercida pelo Governo do Azerbaijão e o envolvimento da UE em termos de reabilitação e assistência tem sido marginal, com fraco impacto nas dinâmicas de transformação positiva dos conflitos. Para além disso, ao tentar manter uma posição equidistante entre a Arménia e o Azerbaijão, a UE tenta reconciliar os princípios da integridade territorial (do Azerbaijão) e da autodeterminação (do Nagorno-Karabakh), sem explicar de que forma isso permite avançar o processo de paz.

No âmbito da negociação dos novos Acordos de Associação, a UE teve uma oportunidade importante de ligar os avanços na integração europeia dos países vizinhos a avanços na resolução destes conflitos. Os AA preveem passos concretos com vista à associação política e à integração económica, nomeadamente a celebração de Acordos de Comércio Livre Aprofundados e Abrangentes (DFCTA) entre a UE e os Estados da Parceria Oriental (PO) que cumpram os critérios relevantes. Incluem também passos importantes com vista à liberalização de vistos, prevendo-se um impacto real na vida dos cidadãos (esta questão é desenvolvida em mais pormenor em baixo). No entanto, tendo em conta a diversidade de ambições da região nas relações com a UE e a competição crescente entre as políticas de vizinhança da UE e da Rússia, no Cáucaso do Sul, apenas a Geórgia assinou o Acordo de Associação com a UE, enquanto a Arménia decidiu abandonar as negociações do AA e participar na União Económica da Eurásia (UEE), tendo assinado com a UE apenas um Acordo de Parceria Abrangente e Avançado. O Azerbaijão, por seu

5 O Grupo de Minsk da OSCE é o formato negocial oficial para o conflito do Nagorno-Karabakh, criado em 1992 pela então Conferência para a Segurança e Cooperação na Europa (CSCE). O grupo é copresidido pela França, a Federação Russa e os Estados Unidos e os membros permanentes são a Alemanha, a Bielorrússia, a Itália, a Finlândia, a Suécia e a Turquia, bem como a Arménia e o Azerbaijão. Numa base rotativa, a Presidência da OSCE é também um membro permanente do Grupo de Minsk. Não estão incluídos representantes de Nagorno-Karabakh. 
lado, está também em negociações para um acordo estratégico, mais limitado, que reflita os interesses específicos do país nas relações com a UE e a sua política multivetorial. A revisão da PEV em 2015 sublinhou essa necessidade de flexibilizar e ajustar as ofertas da UE às necessidades de cada parceiro (Comissão Europeia e Alta Representante da União Europeia para os Negócios Estrangeiros e a Política de Segurança, 2015b), procurando ultrapassar as limitações criadas pela fraca adesão dos Estados da região aos AA.

\section{Difusão de Influência Regional pelo Comércio e a Liberalização de Vistos}

A liberalização do comércio e dos vistos é um dos incentivos mais apelativos à participação na PEV e, em particular, na sua dimensão leste, a PO ${ }^{6}$ Uma possível participação no mercado interno da UE representaria uma possibilidade importante de crescimento económico e modernização para estas sociedades. Por outro lado, a remoção de vistos para estadias curtas no espaço da UE tem um impacto concreto na vida dos cidadãos. Num contexto regional de competição com a Rússia, em que a autoridade moral, democrática e financeira da UE se encontra fragilizada pelas múltiplas crises que a têm abalado, a capacidade da PO incentivar reformas e de promover medidas de apoio ao bem-estar social e à democratização é bastante incerta.

\subsection{Geórgia}

A Geórgia é o parceiro mais avançado da UE na PO e no Cáucaso do Sul. O apoio popular à opção da integração Euro-atlântica do país permanece elevado e mantém-se o consenso entre as elites de diferentes quadrantes políticos sobre esta opção de política externa, que um membro do governo apelidou de "Europeização irreversível" (Zalkaliani, 2004. Ver também Kakachia, 2015). Apesar das dificuldades de implementação e dos potenciais impactos negativos que a liberalização do comércio pode ter para a Geórgia (Manoli, 2013), a integração Euro-Atlântica funciona como um elemento de coesão política face à ameaça externa da Rússia (Tsutskiridze, 2011). A insegurança política e militar tem sido um incentivo importante nas relações de Tbilisi com Bruxelas, uma vez que estas se têm desenvolvido de forma paralela com a NATO. Mais de dez anos depois da inclusão da Geórgia e os restantes Estados da região na PEV, a assinatura dos AA permite finalmente desenvolver estas relações políticas num novo patamar. A implementação inicial dos AA e dos Planos de Ação com vista à Liberalização de Vistos por parte dos países parceiros abrangidos pelos AA, mesmo antes da sua ratificação pelos 28 Estados membros da UE, ilustra bem o nível de compromisso das partes. As trocas comerciais entre a UE e a Geórgia aumentaram 7 por cento desde

6 A Parceria Oriental foi criada em 2009 e engloba os seis Estados da Europa de Leste e Cáucaso do Sul participantes na PEV, nomeadamente: Arménia, Azerbaijão, Bielorrússia, Geórgia, Moldova e Ucrânia. 
que a DCFTA entrou em vigor (Comissão Europeia, 2015) e em 2017 a UE liberalizou os vistos para cidadãos georgianos em visitas curtas aos países da UE. Para além disso, a UE é o maior doador à Geórgia, providenciando assistência financeira e técnica num número amplo de áreas, ${ }^{7}$ tornando assim a assistência da UE às reformas da Geórgia num aspeto crucial da sua modernização e da manutenção de padrões elevados de democracia e direitos humanos.

Procurando avançar esta agenda de reformas, o Relatório de Progresso de 2014 sobre a Geórgia sublinha a necessidade de apoiar o desenvolvimento de capacidades autónomas, assistindo o país no desenvolvimento de competências técnicas e institucionais necessárias à implementação das regulamentações europeias (Comissão Europeia e Alta Representante da UE para os Negócios Estrangeiros e Política de Segurança, 2015a). Este é um dos desafios maiores que se colocam aos parceiros da UE, especialmente num contexto de competição com a Rússia (Piet e Simão, 2016; Delcour, 2015). Por exemplo, as alterações necessárias na gestão fronteiriça da Geórgia têm impacto na forma como o comércio com os países vizinhos é feito (nomeadamente com a Arménia, o Azerbaijão e a Rússia), mas também com as regiões separatistas da Abecásia e da Ossétia do Sul. Nesse sentido, apesar das relações difíceis, o comércio continua entre as duas margens do rio Ingur/i, que separa a Abecásia do território georgiano, e há aqui importantes oportunidades de regulamentação, que poderiam servir como elementos de criação de confiança entre as partes (Mirimanova, 2015). O aprofundamento das relações comerciais entre a Geórgia e a UE, por um lado, e entre a Abecásia e a Ossétia do Sul com a Rússia, por outro, marcam duas direções opostas, levantando questões de compatibilidade das regras que definem as interações económicas e comerciais transfronteiriças. Na ausência de regras compatíveis e caso a UE não seja capaz de contribuir para soluções comuns, isso poderá diminuir o potencial impacto positivo do comércio e da própria PEV na transformação dos conflitos.

Um argumento semelhante pode ser feito relativamente aos potenciais impactos negativos que a atual política de vistos da UE pode ter nas dinâmicas dos conflitos na Geórgia. Logo em 2007, o Governo da Geórgia manifestou a sua preocupação com as negociações da UE com a Rússia relativas a um futuro acordo de facilitação de vistos, que previa pudesse vir a ter um impacto negativo nas relações de Tbilisi com as regiões separatistas da Abecásia e da Ossétia do Sul (Burjanadze, 2007). Devido à política russa de atribuição de passaportes aos habitantes destas duas regiões, o Governo da Geórgia temia que a facilitação de vistos para a UE a quem possuísse um passaporte russo viesse a constituir um incentivo negativo à aproximação destas regiões a Tbilisi. Este argumento teve um papel central no avanço do diálogo UE-Geórgia sobre facilitação de vistos, que resultou na adoção de uma Parceria para a Mobilidade, assinada em novembro de 2009. A cooperação com a UE em matéria de Justiça e Assuntos Internos tem sido um incentivo importante

7 Informação detalhada sobre os diferentes esquemas de financiamento da UE à Geórgia, disponível em http://eeas.europa.eu/factsheets/news/eu-georgia_factsheet_en.htm 
para a delimitação das fronteiras no Cáucaso do Sul, uma área central para a estabilidade regional. No caso da Geórgia, a delimitação da fronteira com a Rússia tem um impacto direto nas dinâmicas dos conflitos, não só porque os territórios da Abecásia e da Ossétia do Sul se situam nessa fronteira, mas também porque implicam um reconhecimento das práticas de criação de fronteiras por parte da Rússia (Kakachia, 2013). ${ }^{8}$

A guerra na Geórgia em 2008 foi um ponto de viragem nas relações da UE com os seus vizinhos de leste, criando as condições para um consenso interno sobre a necessidade de apresentar incentivos mais significativos à aproximação destes países à UE. No centro da condicionalidade da UE permanecem as reformas políticas e económicas, mas a importância de apoiar um parceiro estratégico e entusiasta da integração euro-atlântica tem permitido ultrapassar as dificuldades ligadas às limitações e divergências com Tbilisi nos dois campos. A Geórgia foi um dos estados da PO mais penalizados pela Federação Russa devido à sua orientação pró-ocidental, incluindo boicotes aos produtos georgianos, a expulsão de migrantes ilegais a viver na Rússia e até uma intervenção militar, entre outras medidas punitivas (Nygren, 2010). Em parte, estas medidas aceleraram a diminuição da dependência da economia georgiana no mercado russo, facilitando assim a decisão de Tbilisi de abandonar a Comunidade de Estados Independentes (CEI) em 2009 (RFE/ RL, 2009). Em 2007, a Geórgia terminou os acordos com a Rússia para a permanência de bases militares russas no seu território, em Akhlkalaki e Batumi. Estas escolhas acarretaram um preço elevado, uma vez que, após a guerra dos cinco dias em agosto de 2008, a Rússia decidiu reconhecer as declarações de independência da Abecásia e da Ossétia do Sul e desenvolveu medidas que levaram à sua integração de facto na Federação Russa, incluindo novos acordos de cooperação militar que reforçaram a presença militar russa nessas regiões. Assim, podemos dizer que a PO se tem revelado uma ferramenta fraca na promoção da segurança do território georgiano (Whitman e Wolff, 2010), ao passo que as reformas internas permanecem frágeis e as desigualdades económicas elevadas.

\subsection{Azerbaijão}

A base legal das relações da UE com o Azerbaijão permanece o APC de 1999, uma vez que as duas partes não conseguiram ainda definir um novo acordo político. Apesar da importância estratégica do Azerbaijão para a estratégia europeia de diversificação energética, incluindo no âmbito do Corredor Energético Sul, as relações entre os dois parceiros permanecem difíceis. Em 2006 foi assinado um memorando de entendimento no campo energético, estabelecendo uma Parceria Estratégica no campo da Energia, e tem sido mantido um

8 A prática de criação de fronteiras refere-se a um conjunto de atividades promovidas pela Federação Russa que incluem a deslocação da sinalética de fronteira administrativa entre as regiões separatistas e a Geórgia, bem como a instalação de equipamentos como arame farpado, criando uma presença física da fronteira que não existia antes. 
diálogo regular no âmbito das instituições bilaterais criadas pelo APC. No entanto, a natureza autoritária e repressiva do regime em Bacu e as crescentes tensões relativas a prisioneiros políticos e a violações de direitos humanos, bem como a perspetiva instrumental de Bacu relativamente às relações com a UE têm criado dificuldades nas relações entre os dois atores (TOL, 2015). Ilustrando estas dificuldades, a inclusão na PEV em 2004 e a implementação do Plano de Ação bilateral tiveram um impacto limitado na capacidade da UE influenciar o contexto político do país. Para além disso, os líderes europeus apreciam genuinamente a política externa multivetorial do Azerbaijão e a sua procura de autonomia face a Moscovo, limitando a capacidade de a União impor condicionalidade política (Yunusov, 2007). Desde 2013 estão em curso negociações para um novo acordo que o Azerbaijão gostaria que fosse uma Parceria Estratégica de Modernização, onde o equilíbrio entre condicionalidade política e reformas democráticas, por um lado, e a apoio à integridade territorial e acesso a tecnologia de ponta, por outro, procura ser alcançado (Rettman, 2013). Esta abordagem ilustra bem as ambições divergentes que sustentam estas relações.

As relações comerciais da UE com o Azerbaijão permanecem limitadas, uma vez que Bacu não é ainda membro da Organização Mundial do Comércio (OMC) e que a sua economia depende em larga medida da exportação de energia (Valiyev, 2011). Assim, apesar do crescente volume de comércio bilateral e investimento, o interesse do Azerbaijão em estabelecer uma DCFTA com a UE permanece muito limitado. Tal como a ideia de uma Parceria Estratégica para a Modernização sugere, o maior interesse do Azerbaijão é garantir acesso a fundos e tecnologia europeias, bem como garantir algum nível de diversificação da economia. As relações económicas com a Rússia são também fundamentais para o Azerbaijão, quer em termos energéticos, quer em produtos não-energéticos. Apesar do impacto negativo das sanções impostas a Moscovo pela UE e outros Estados desde 2014, Bacu tem defendido uma política externa que evita compromissos exclusivos com um qualquer projeto de integração regional. Assim, a PEV e a DCFTA prevista no âmbito da PO têm tido uma capacidade limitada de ancorar o país à integração europeia.

Relativamente às questões fronteiriças e de vistos, a UE e o Azerbaijão celebraram três acordos bilaterais sobre facilitação de vistos, readmissão e uma parceria para a mobilidade. Os controlos fronteiriços têm sido uma preocupação crescente do Azerbaijão desde a adoção da Estratégia de Segurança Nacional de 2007. O Governo reconhece que o Azerbaijão está localizado num cruzamento estratégico, tornando-se uma rota privilegiada para o crime organizado (Ministério da Segurança Nacional da República do Azerbaijão, 2014). Procurando responder a estes desafios, o Azerbaijão adotou uma nova política migratória, modernizou os seus serviços migratórios e fronteiriços e aprofundou a sua cooperação com organizações internacionais, incluindo com a UE (Ceccorulli, 2015). O apoio da UE à criação de uma Estratégia Integrada de Gestão de Fronteiras foi uma ferramenta importante para o Governo do Azerbaijão. A criação de capacidades nestas matérias é fundamental para a facilitação do comércio, mas também para questões securitárias, 
permitindo um aumento de trocas de informação entre a UE e os seus parceiros regionais. A demarcação de fronteiras com a Rússia e a Geórgia avançou, mas devido à disputa com a Arménia pelo território de Nagorno-Karabakh, não tem sido possível qualquer avanço na demarcação desta fronteira comum.

Em parte, as relações delicadas, mas simultaneamente estratégicas, da UE com o Azerbaijão explicam o envolvimento limitado da União no processo de mediação do conflito de Nagorno-Karabakh. Ao passo que a Arménia tem procurado manter os atuais três copresidentes do Grupo de Minsk (a França, a Rússia e os EUA), o Azerbaijão tem discutido a possibilidade de a UE ser incluída na mediação, uma vez que o atual formato lhe parece claramente favorável aos interesses da Arménia (Shiriyev, 2013). ${ }^{9}$ No entanto, o Azerbaijão continua sem permitir que a UE visite a região do Nagorno-Karabakh, nomeadamente o seu REUE, impedindo o desenvolvimento de uma política mais focada na criação de confiança. Por seu lado, a UE tem hesitado em colocar de forma central o tema do conflito na agenda bilateral com o Azerbaijão, uma vez que considera não ter influência sobre a política do governo do Azerbaijão. Com o aumento dos orçamentos de defesa a disparar na região (SIPRI, 2014) e a retórica provocatória a ser usada para manter elevados níveis de apoio popular aos regimes, a UE precisa trabalhar de forma mais próxima com os seus parceiros em medidas de criação de confiança para evitar a escalada dos conflitos.

\subsection{Arménia}

As relações da Arménia com a UE têm a sua base legal no APC de 1999 e foram revistas e atualizadas com a adoção do Plano de Ação bilateral no âmbito da PEV, em 2006. Apesar do estado avançado das negociações entre os dois parceiros para um novo Acordo de Associação, incluindo uma DCFTA, em 2013 o governo arménio decidiu não se comprometer com o acordo negociado. Em vez disso, foi anunciada a decisão (surpresa) de aderir à UEE, incluindo à sua União Aduaneira, a partir de janeiro de 2015. Este volte-face tem impacto significativo na capacidade da UE influenciar as dinâmicas regionais do Cáucaso do Sul e na possibilidade de a PO se traduzir em influência significativa na região. Na realidade, ao centrar-se na promoção de reformas sectoriais e aplicando condicionalidade política muito limitada, a PO tem-se posicionado como um instrumento de influência regional com enfoque na lógica de extensão da governação da UE. O Governo arménio tem, assim, beneficiado amplamente da cooperação sectorial com a UE em áreas chave das reformas económicas e administrativas, sem assumir os custos que essas reformas implicaram para as elites no governo (Delcour e Wolczuk, 2015). Para além disso, as relações próximas da Arménia com a UE têm também oferecido importantes alternativas à política externa do país, num contexto geopolítico difícil. Ilustrando a sensibilidade da

9 O Governo do Azerbaijão sublinha a presença de importantes diásporas arménias em França, na Rússia e nos EUA, fazendo lobby ativo para que a posição destes países seja favorável a Erevan. 
UE para esta questão, apesar de abandonarem o Acordo de Associação, Bruxelas e Erevan conseguiram concluir um novo acordo bilateral que respeite os novos compromissos do país no âmbito da UEE.

A Arménia apresenta-se assim como um estudo de caso sobre a capacidade da PO permitir à UE exercer influência regional na ausência de acordos comerciais compreensivos. Uma vez que o Governo arménio continua muito interessado em desenvolver relações próximas com a UE e em beneficiar do leque amplo de programas de apoio e financiamento de reformas, a Comissão Europeia tem aqui um incentivo extra para desenvolver um acordo comercial que seja compatível com a UEE. Isto refletiria também as prioridades estabelecidas na revisão da PEV, de 2015, sobre a necessidade de desenhar acordos comerciais flexíveis e seria um passo importante para reduzir tensões na vizinhança partilhada com a Federação Russa. No atual contexto, a UE mantém um perfil de doador na Arménia, com capacidade limitada de exercer influência política ou de desenvolver uma parceria de longo prazo com as autoridades do país (Babayan, 2011). De facto, a dependência da Arménia em relação à Rússia, ao nível económico, financeiro e militar é exacerbada pela permanência do conflito de Nagorno-Karabakh, impedindo o governo arménio de prosseguir mudanças significativas na sua política externa que possam por em causa o status quo (de Waal, 2015). Para a Arménia, assinar o AA com a UE representaria uma opção muito mais complexa do que a dimensão económica sugere. As razões de segurança evocadas pelo Presidente Arménio para não assinar o AA e optar pela adesão à UEE tornaram claro o nível de influência da Rússia sobre o país. ${ }^{10}$ Esta escolha impos custos económicos pesados à Arménia, já que a economia russa vive um período de desaceleração, devido aos preços baixos do petróleo e às sanções internacionais de que é alvo desde a anexação da Crimeia, em Março de 2014. Contudo, a Arménia tem beneficiado de assistência financeira da UE e outras organizações internacionais, como o Fundo Monetário Internacional e o Banco Mundial.

A guerra na Geórgia, em 2008, afetou negativamente uma das artérias principais ligando a Arménia à Rússia. Aproveitando este contexto, o Presidente arménio e o Presidente turco iniciaram uma série de encontros diplomáticos com vista à normalização das relações entre os dois países e que ficaram conhecidos como a "diplomacia de futebol". Apesar de o objetivo de normalização das relações bilaterais não ter sido atingido, nomeadamente devido à questão do genocídio arménio de 1915 e à pressão do Azerbaijão sobre a Turquia para que não levantasse o bloqueio à Arménia ligado ao conflito de Nagorno-Karabakh, foram iniciadas importante mudanças em ambas as sociedades facilitando as trocas transfronteiriças (Hill, Kirişci e Moffatt, 2015; ESI, 2009). A UE apoiou estes

10 Para além da Abecásia e da Ossétia do Sul, a Arménia é agora o único país do Cáucaso do Sul onde a Rússia tem bases militares, tornando-a num elemento de grande valor estratégico para a política externa e de segurança da Rússia. 
esforços diplomáticos ${ }^{11}$, mas foi incapaz de usar o já frágil processo de adesão da Turquia à União e a participação da Arménia e do Azerbaijão na PEV/PO para criar incentivos significativos para todas as partes com vista a sustentar a mudança de status quo na região.

Apesar da falta de progresso nas relações políticas com a UE, foram concluídos acordos de facilitação de vistos e de readmissão com a Arménia, que entraram em vigor em janeiro de 2014, preparando assim o caminho para a futura liberalização de vistos. Para a Arménia, a liberalização de vistos é um aspeto importante, já que uma parte significativa da sua diáspora vive em países da UE. Para além disso, a Arménia tem duas fronteiras fechadas, com a Turquia e o Azerbaijão, e a fronteira com o Irão teve uma importância marginal em termos económicos, durante a maior parte da sua independência, devido à imposição de sanções internacionais ao regime de Teerão. Assim, a fronteira com a Geórgia assume uma importância fulcral, apesar das flutuações nas relações de Tbilisi com Moscovo.

\section{Conclusões}

As relações da UE com os países do Cáucaso do Sul ilustram perfeitamente os dilemas da PEV/PO em promover estabilidade na periferia da UE com base na exportação do modelo de governação da UE, na ausência de perspetivas de adesão e num contexto de grande contestação e competição regional (Simão, 2018). Efetivamente, o enfoque em reformas técnicas tem permitido à UE manter relações com parceiros cuja base normativa é altamente divergente da sua, mas tem também com isso reduzido a sua capacidade de alcançar os seus objetivos estratégicos de se afirmar como o principal parceiro da região. Embora a UE rejeite a linguagem das esferas de influência e não se veja como uma potência hegemónica, a realidade é que os seus modelos governativos, regulatórios e normativos visam criar condições favoráveis ao exercício de poder. Isso significa que, em última análise, a PEV/PO é um instrumento altamente político (Simão, 2017) que se deve assumir como tal.

A politização da PEV/PO permitiria uma discussão mais abrangente e construtiva sobre as prioridades comuns que a parceria da UE com os seus vizinhos a leste permite avançar. Tal como está desenhada e implementada, neste momento, a PEV/PO não permite ainda uma definição das prioridades de reforma pelos vizinhos e reflete acima de tudo a visão que a própria União tem do espaço pan-europeu. Não só isso representa um imenso desperdício de capital inovador, como acaba por deslegitimar e desmotivar alguns dos seus parceiros. Assim, a abertura, ainda que tardia e difícil, à liberalização do comércio e de vistos é um passo positivo, mas que peca pela sua insuficiência. Em particular, é notória a ausência de uma visão clara sobre o futuro dos conflitos regionais, onde este envolvimento crescente da UE se traduza na sua transformação positiva.

11 Nomeadamente através do programa "Support to the Armenia-Turkey Normalisation Process", financiado pelo Instrumento para a Estabilidade. Informação disponível em http://www.armenia-turkey. net/en/programme. 


\section{Bibliografia}

BABAYAN, Neli - Armenia: Why the European Neighbourhood Policy has failed. FRIDE Policy Brief, No. 68 (fevereiro 2011).

BURJANADZE, Nino - Non-paper on Visa Facilitation and Readmission Issues between Georgia and the EU. Comunicação da Presidente do Parlamento georgiano na Conferência IPEX, Bratislava, 2007.

COMISSÃO EUROPEIA - Wider Europe Neighbourhood: A New Framework for Relations with Our Eastern and Southern Neighbours. Communication from the Commission to the Council and the European Parliament. COM (2003) 104 final, Bruxelas (4 março 2003).

COMISSÃO EUROPEIA - European Neighbourhood Policy - Strategy Paper. Communication from the Commission. COM (2004) 373 final, Bruxelas (12 maio 2004).

COMISSÃO EUROPEIA - EU-Armenia ENP Action Plan, Bruxelas (2006a).

COMISSÃO EUROPEIA - EU-Azerbaijan ENP Action Plan, Bruxelas (2006b).

COMISSÃO EUROPEIA - EU-Georgia ENP Action Plan, Bruxelas (2006c).

COMISSÃO EUROPEIA - EU-Georgia Trade: Deep and Comprehensive Free Trade Area Fact-Sheet, DG Trade (2015).

COMISSÃO EUROPEIA e ALTA REPRESENTANTE DA UNIÃO EUROPEIA PARA OS NEGÓCIOS ESTRANGEIROS E A POLÍTICA DE SEGURANÇA (2015a) Implementation of the European Neighbourhood Policy in Georgia Progress in 2014 and recommendations for actions, Joint Staff Working Document accompanying the Joint Communication to the European Parliament, the Council, the European Economic and Social Committee and the Committee of the Regions. SWD(2015) 66 final, Bruxelas (25 março 2015a).

COMISSÃO EUROPEIA e ALTA REPRESENTANTE DA UNIÃO EUROPEIA PARA OS NEGÓCIOS ESTRANGEIROS E A POLÍTICA DE SEGURANÇA - Review of the European Neighbourhood Policy, Joint Communication to the European Parliament, the Council, the European and Social Committee and the Committee of the Regions. JOIN(2015) 50 final, Bruxelas (18 de novembro 2015b).

CONSELHO da UE e COMISSÃO EUROPEIA - Decision on the conclusion of the Partnership and Cooperation Agreement between the European Communities and their Member States, of the one part, and the Republic of Armenia, of the other part. 1999/602/ EC, ECSC, Euratom, (31 maio 1999a).

CONSELHO da UE e COMISSÃO EUROPEIA - Decision on the conclusion of the Partnership and Cooperation Agreement between the European Communities and their Member States, of the one part, and the Republic of Azerbaijan, of the other part. 1999/614/EC, ECSC, Euratom (31 maio 1999b).

CONSELHO da UE e COMISSÃO EUROPEIA - Decision on the conclusion of the Partnership and Cooperation Agreement between the European Communities and their 
Member States, of the one part, and Georgia, of the other part. 1999/515/EC, ECSC, Euratom (31 maio 1999c).

CONSELHO da UE - Joint Action 2003/496/CFSP,OJ L 169, 8.7.2003a

CONSELHO da UE - Joint Action 2003/872/CFSP, OJ L 326, 13.12.2003b

CONSELHO da UE - Joint Action 2004/523/CFSP, OJ L 228/21. 29.6.2004a

CONSELHO da UE - Joint Action 2004/532/CFSP, OJ L 234, 3.7.2004b

CONSELHO da UE - Joint Action 2005/100/CFSP, OJ L 31, 4.2.2005

COPPIETERS, Bruno - The Caucasus as a security complex. In COPPIETERS, Bruno Contested Borders in the Caucasus. Bruxelas: VUB Press, 1996, pp. 193-204.

COPPIETERS, Bruno - The EU and Georgia: Time perspectives in conflict resolution. European Union Institute for Security Studies Occasional Paper, No. 70 (dezembro 2007).

CORNELL, Svante E. - Small Nations and Great Powers: A Study of Ethnopolitical Conflict in the Caucasus. London: Curzon Press, 2000.

de WAAL, Thomas - Black Garden. Armenia and Azerbaijan through peace and war. New York: New York UP, 2003.

de WAAL, Thomas - The Caucasus. An Introduction. Oxford: Oxford UP, 2010.

de WAAL, Thomas - Losing Control in the Caucasus. Politico Europe (11 outubro 2015).

DELCOUR, Laure - Between the Eastern Partnership and Eurasian Integration: Explaining Post-Soviet Countries' Engagement in (Competing) Region-Building Projects. Problems of Post-Communism. Vol. 62: No. 6 (2015), pp. 316-327.

DELCOUR, Laure and WOLCZUK, Kataryna - The EU's Unexpected 'Ideal Neighbour'? The Perplexing Case of Armenia's Europeanisation. Journal of European Integration. Vol. 37: No. 4 (2015), pp. 491-507.

ESI - Noah's Dove Returns: Armenia, Turkey and the Debate on Genocide. Istambul: European Stability Initiative, 2009.

FEDERAÇÃO RUSSA E UNIÃO EUROPEIA - 300th anniversary of St.-Petersburg celebrating three centuries of common European history and culture. EU-Russia Summit Joint Statement, 9937/03 (Presse 154), St.-Petersburg (31 maio 2009).

HELLY, Damien - EUJUST THEMIS in Georgia: An ambitious bet on rule of law. In NOWAK, Agnieszka - Civilian Crisis-Management: The EU way. Paris: EU Institute for Security Studies, 2006.

HELLY, Damien - EU's influence in its Eastern Neighbourhood: The case of Crisis Management in the Southern Caucasus. European Political Economy Review. Vol. 7 (2007), pp. 102-117. 
HILL, Fiona; KIRIŞCI, Kemal e MOFFATT, Andrew - Armenia and Turkey: From normalization to reconciliation. Turkish Policy Quarterly. Vol. 13: No. 4 (2015), pp. 127-138.

ICG - Conflict Resolution in the South Caucasus: The EU's Role. International Crisis Group, Europe Report, No. 173 (20 março 2006).

IIFFMCG - Report of the Independent International Fact-Finding Mission on the Conflict in Georgia. Vol. II (setembro 2009).

KAKACHIA, Kornely - The politics of insecurity: Cross-border conflict dynamics and security challenges in Georgia, in ERGUN, A and ISAXANLI, H. - Security and Cross-Border Cooperation in the EU, the Black Sea Region and Southern Caucasus, Amsterdam: IOS Press, 2013, pp. 152-166.

KAKACHIA, Kornely - Europeanisation and Georgian foreign policy, in The South Caucasus: Between integration and fragmentation. Baku and Brussels: SAM and EPC, 2015, pp. 11-18.

LYNCH, Dov - Engaging Eurasia's Separatist States. Washington D.C.: United States Institute of Peace Press, 2004.

LYNCH, Dov - Why Georgia matters. European Union Institute for Security Studies, Chaillot Paper, No. 86 (1 fevereiro 2006).

MANOLI, Panagiota - Political Economy aspects of Deep and Comprehensive Free Trade Agreements. Eastern Journal of European Studies. Vol. 4: No. 3 (2013), pp. 51-73.

MINISTRY OF NATIONAL SECURITY OF AZERBAIJAN REPUBLIC - Combating Organised Crime. 2014 [24 outubro 2017]. Available at: http://www.mns.gov.az/en/ pages/47-123.html.

MIRIMANOVA, Natalia - Regulation of Trade across Contested Borders: The cases of China/Taiwan, Serbia/Kosovo and Cyprus. Volume editado. International Alert (abril 2015).

NYGREN, Bertil - Russia and Georgia - from confrontation to war: what is next?. In Kanet, Roger E. - Russian Foreign Policy in the 21st Century. Basingstoke: Palgrave Macmillan, 2010, pp. 101-120.

PARLAMENTO EUROPEU - Resolution on the European Neighbourhood Policy, P6_TA-PROV(2006)0028 (19 janeiro 2006).

PARLAMENTO EUROPEU - Resolution on the Need for an EU Strategy for the South Caucasus, P7_TA(2010)0193 (20 maio 2010).

PIET, Remi e SIMÃO Licínia - Security in Shared Neighbourhoods: Foreign Policy of Russia, Turkey and the EU. Londres: Palgrave Macmillan, 2016.

POPESCU, Nicu - EU Foreign Policy and Post-Soviet Conflicts: Stealth Intervention. Londres: Routledge, 2011.

RETTMAN, Andrew - Azerbaijan and EU race to agree "modernisation" pact. EUobserver (27 setembro 2013). 
RFE/RL - Georgia Finalizes Withdrawal from CIS. Radio Free Europe/Radio Liberty (18 Agosto 2009).

SAMOKHVALOV, Vsevolod - Relations in the Russia-Ukraine-EU triangle: "zero-sum game" or not?. EU Institute for Security Studies Occasional Paper, No. 68 (1 setembro 2007).

SASSE, Gwendolyn - The European Neighbourhood Policy: Conditionality Revisited for the EU's Eastern Neighbours. Europe-Asia Studies. Vol. 60: No. 2 (2008), pp. 295-316.

SASSE, Gwendolyn - The European Neighbourhood Policy and Conflict management: A comparison of Moldova and the Caucasus. Ethnopolitics, Vol. 8: No. 3 (2009), pp. 369-386.

SHIRIYEV, Zaur - Challenges for the EU in the resolution of the Nagorno-Karabakh conflict: An Azerbaijani perspective. European Policy Centre Policy Brief (17 julho 2013).

SIMÃO, Licínia - Region-building in the Eastern Neighbourhood: Assessing EU Regional Policies in the South Caucasus. East European Politics. Vol. 29: No. 3 (2013), pp. 273-288.

SIMÃO, Licínia - The EU's Conflict Resolution Policies in the Black Sea Area. Journal of Balkan and Near Eastern Studies. Vol. 16: No. 3 (2014), pp. 300-313.

SIMÃO, Licínia - Bringing 'the political' back into European security: challenges to the EU's ordering of the Eastern Partnership. East European Politics. Vol. 33: No. 3 (2017), pp. 338-354

SIMÃO, Licínia - The EU's Neighbourhood Policy towards the South Caucasus: Expanding the European Security Community. Londres. Palgrave Macmillan, 2018.

SIMÃO, Licínia e FREIRE, Maria R. - The EU's Neighbourhood Policy and the South Caucasus: Unfolding new patterns of cooperation. Caucasian Review of International Affairs. Vol. 2: No. 4 (2008), pp. 47-61.

SIPRI - SIPRI Military Expenditure Database. 2014 [24 outubro 2017]. Disponível em http://www.sipri.org/research/armaments/milex/milex_database.

SOLANA, Javier - Summary of the introductory remarks by the EU High Representative for the CFSP, press conference in Tbilisi, Georgia, 15 January 2004, S0012/04.

STARR, S. Frederik e CORNELL, Svante E. - The Baku-Tbilisi-Ceyhan Pipeline: Oil Window to the West. Volume editado. Washington D.C. e Uppsala: Central Asia-Caucasus Institute \& Silk Road Studies Program, 2005.

TOL - Azerbaijan Halts EU Visit over Human Rights Rebuke. Transitions Online (15 setembro 2015).

TSUTSKIRIDZE, Levan - Balancing vs. Bandwagoning: Explaining Georgia's Alignments in Security Institutions, in JAFALIAN, Annie - Reassessing Security in the South Caucasus: Regional Conflicts and Transformation. Farnham: Ashgate, 2011, pp. 195-208. 
VALIYEV, Anar - Azerbaijan's Economic Model and its Development since Independence' in South Caucasus - 20 Years of Independence. Berlim: Friedrich-Ebert-Stiftung, 2011, pp. 218-239.

WELT, Cory - Explaining Ethnic Conflict in the South Caucasus: Mountainous Karabagh, Abkhazia, and South Ossetia, Ph.D. Dissertation, Boston: MIT, 2004.

WHITMAN, Richard e WOLFF, Stefan - The EU as a Conflict Manager? The case of Georgia and its implications. International Affairs. Vol. 86: No. 1 (2010), pp. 87-107.

YUNUSOV, Arif - Azerbaijan in the Early XXI Century: Conflicts and Potential Threats, Bacu: Adiloglu, 2007.

ZALKALIANI, Davit - Georgian Foreign Policy in a New Era. Summary of roundtable held at Chatham House, Russia and Eurasia Programme Meeting Summary (18 março 2014). 